Review

\title{
Regulation of exosome production and cargo sorting
}

\author{
Hong Wei2,3, Qi Chen ${ }^{1,3}$, Li Lin ${ }^{1,3}$, Chunli Sha1,3, Taoqiong Li1,3, Yueqin Liu1,3, Xinming Yin 1,3, Yuhao Xu ${ }^{5}$, Lu \\ Chen ${ }^{1,3}$, Wujiang Gao ${ }^{1,3}$, Yuefeng $\mathrm{Li}^{\bowtie}$ and Xiaolan $\mathrm{Zhu}^{1,3}$ \\ 1. Reproductive Center, The Fourth Affiliated Hospital of Jiangsu University, Zhenjiang, Jiangsu, 212001, China. \\ 2. Department of Neurology, Affiliated ZhongDa Hospital, School of Medicine, Southeast University, Nanjiang, Jiangsu, 210009, China. \\ 3. Central Laboratory of the Fourth Affiliated Hospital of Jiangsu University, Zhenjiang, Jiangsu, 212001, China. \\ 4. Department of Radiology, The Affiliated Hospital of Jiangsu University, Zhenjiang, Jiangsu, 212001, China. \\ 5. Department of Neurology, The Affiliated Hospital of Jiangsu University, Zhenjiang, Jiangsu, 212001, China. \\ $\square$ Corresponding authors: E-mail: zx12517@163.com; jiangdalyf@163.com. \\ (1) The author(s). This is an open access article distributed under the terms of the Creative Commons Attribution License (https://creativecommons.org/licenses/by/4.0/). \\ See http://ivyspring.com/terms for full terms and conditions.
}

Received: 2020.09.24; Accepted: 2020.II.0I; Published: 2021.01.0I

\begin{abstract}
Cellular communication can be mediated by the exchange of biological information, mainly in the form of proteins and RNAs. This can occur when extracellular vesicles, such as exosomes, secreted by a donor cell are internalized by an acceptor cell. Exosomes bear specific repertoires of proteins and RNAs, indicating the existence of mechanisms that control the sorting of molecules into them. Knowledge about loadings and processes and mechanisms of cargo sorting of exosomes is essential to shed light on the physiological and pathological functions of these vesicles as well as on clinical applications involving their use and/or analysis. In this review, we will discuss the molecular mechanisms associated with exosome secretion and their specific cargo sorting, with special attention to the sorting of RNAs and proteins, and thus the outcome and the emerging therapeutic opportunities of the communication between the exosome-producer and recipient cells.
\end{abstract}

Key words: exosomes; production; cargo; sorting

\section{Biogenesis of exosome}

\section{Biogenesis}

Almost all cells are capable for secreting various types of extracellular vesicles (EVs). In accordance with the origin, functions, and biogenesis, a series of EVs were classified into the following three types: exosomes, microvesicles (MVs)/shedding particles, and apoptosis bodies [1, 2]. The "exosome" was coined to describe a group of nanosized $(30-150 \mathrm{~nm})$ vesicles that are formed inside endosomes and released into the extracellular environment [3]. Exosome biogenesis consists of three processes including the formation of inside endocytic vesicles, the generation of multivesicular bodies (MVBs), and the release of exosomes [4]. Apart from this process, MVBs can also be degraded upon fusion with the lysosome. Similar to the host cells, exosomes possess membrane structures composed of a lipid bilayer and contain all known molecular constituents of host cell, including proteins, DNAs, RNAs, lipids and metabolites (Fig. 1) [5-7]. Essentially, their autocrine, paracrine, and endocrine functions for intracellular or intercellular communication depend on the contents of the exosomes [8].

\section{Isolation}

The isolation of exosome is critical to understanding their mechanisms. Isolation strategies typically used include centrifugation, ultrafiltration, size-exclusion chromatography (SEC), polymer-based precipitation, affinity capture on antibody-coupled magnetic beads, and microfluidics-based technologies [9-11]. The gold standard for exosome isolation is widely considered as centrifugation-based techniques. Besides centrifugation, ultrafiltration is one of the most essential methods for the size-based isolation [12], and this method is currently used in combination with ultracentrifugation. SEC enables size-based separation on a single column, with the majority of exosomes eluting before soluble components such as proteins [13]. Ultrafiltration and SEC techniques have achieved the high-purity preparations of exosomes [14]. Precipitation methods 
have been used to capture and collect exosomes of a certain size by simple, rapid, low-speed centrifugation [15]. Immunoaffinity method is a means via exploit the interactions between proteins and their antibodies and specific interactions between receptors and their ligands [16-18]. Recently, microfluidics-based technologies have gradually become important techniques using both the physical and biochemical properties of exosomes $[19,20]$. The different exosome isolation can affect the analysis and consequently, choosing the appropriate isolation method for different demands should be approached with caution [21].

\section{Characterization}

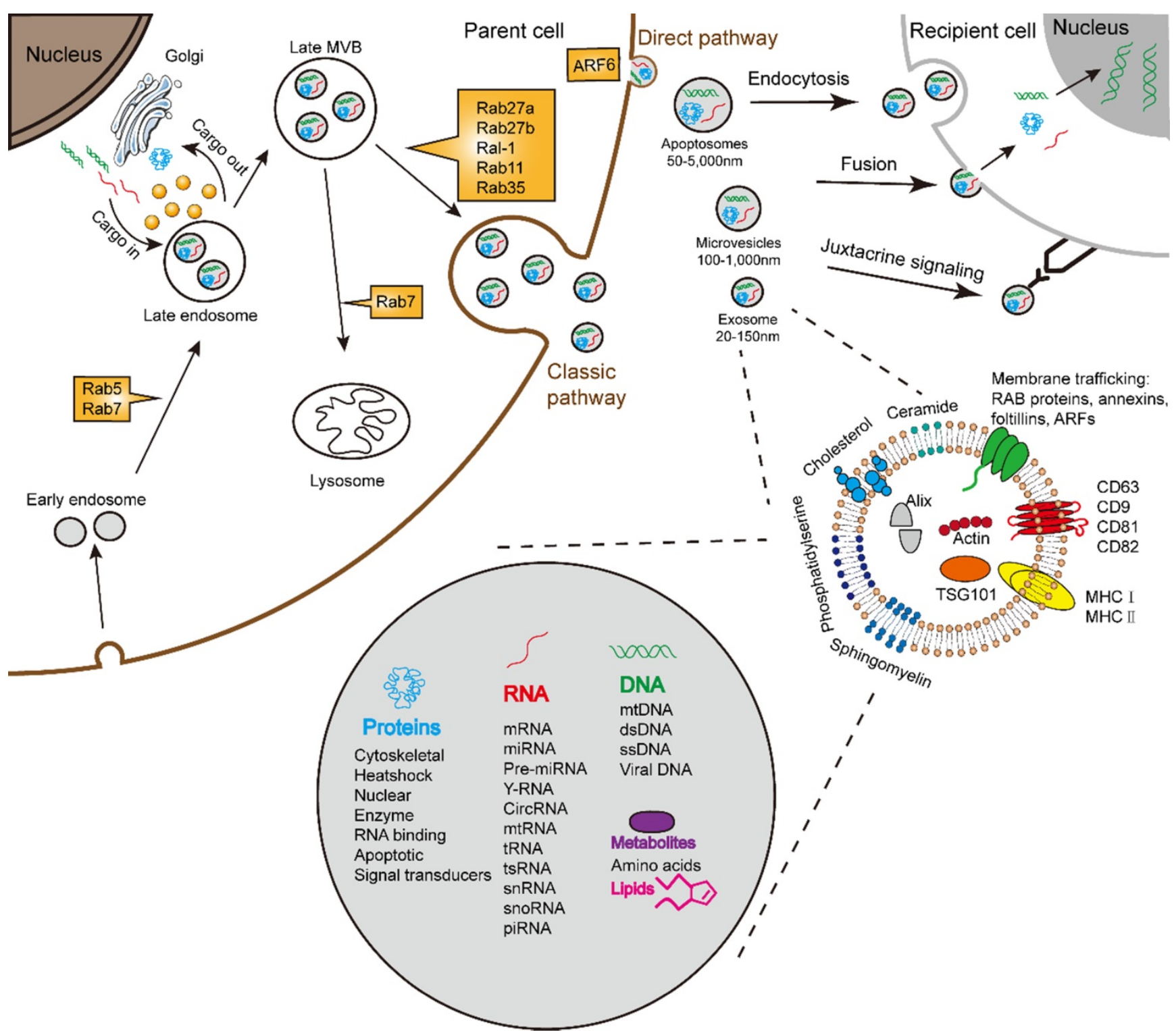

One of the most vexing problems in exosome biology is how to accurately measure and assess exosome purity [22]. The characterization of exosome (such as size, shape, surface charge, and density), is required to determine their action and functions, and hence, the accurate determination of these physicochemical properties are of the utmost importance. There are numerous methods for measuring exosomes, including nanoparticle tracking analyses (NTA), dynamic light scattering (DLS), resistive pulse sensing (RPS), atomic force microscopy (AFM), transmission electron microscopy (TEM), flow cytometry, ELISA, raman spectroscopy, electrochemical detection and microfluidics [23]. NTA can provide the size, size distribution, concentration, and

Figure I. Schematic illustration of exosome biogenesis and composition. Exosomes originate from the inward budding of endosomal multivesicular bodies (MVB). Some of the MVBs formed are transported by associated RAB proteins to fuse with the membrane. MVB can be degraded upon fusion with the lysosome or can release intraluminal vesicles (ILVs) into the extracellular space upon fusion with the plasma membrane. Cells release exosome via the classic pathway and the direct pathway. Subsequently, exosomes can be uptaken by recipient cells via exosomal fusion, endocytosis and juxtacrine signaling to transfer RNA and protein content. Exosomes are surrounded by a phospholipid bilayer and carry various biological species, including proteins, DNA, RNA, lipids and metabolites. 
phenotype of the exosome [24]. The output of DLS is the diameter range of exosome [25]. RPS is an essential method which is most useful for investigating cellular function and uptake, and it works when measuring the size distribution and concentration of exosome [26]. AFM is a unique alternative to optical and electron diffraction techniques for analyzed exosome [24]. TEM is widely used for the visualization of exosome and is used to study the structure, morphology and size of exosome biological components [24]. Flow cytometry is used to study exosomal surface proteins [24]. ELISA is highly suitable for analyzed exosome from complex bodily fluids. Raman spectroscopy can differentiate exosome as a function of the membrane lipid/protein content along with other various surface modifications [27]. Electrochemical detection is widely used for biomolecular analysis [28, 29], and microfluidics has shown great valuable in biological applications [30].

\section{Formation of exosome}

\section{The classic pathway of exosome formation}

The best studied pathway of exosome formation by far is the classic pathway (Fig. 1). The classic process of exosome generating involves double invagination of the plasma membrane and the formation of intracellular MVBs containing ILVs [31]. The most recognized mechanism for formation of exosome is driven by the endosomal sorting complexes required for transport (ESCRT) complexes [32]. The ESCRT is a family of proteins that associate in successive complexes at the membrane of MVBs to sort cargo and the formation of ILVs [33] which are ultimately secreted as exosome through MVB fusion to the plasma membrane and exocytosis [31]. Some components of ESCRT could act selectively on MVE and ILVs for exosome secretion [34]. Besides ESCRT, a recent study demonstrated the significance of syndecan proteoglycans and their cytoplasmic adaptor syntenin in regulating exosome formation [35]. It is reported that exosome biogenesis involves the MVB acidification. Progressive acidification along the endocytic pathway is essential for degradation and recycling of internalized components [36].

A core component of exosome biogenesis involves the ESCRT complexes, while an ESCRTindependent pathway involving ceramides has also been studied [37]. The sorting of proteolipid protein (PLP) into ILVs is ESCRT-independent, which is depend on the sphingolipid ceramide [37, 38]. Additionally, the tetraspanin family had been proved that regulate ESCRT-independent endosomal sorting [39]. The mechanism involved CD63 is required for exosome formation [40]. The Rab-related proteins
(Rabs) family including several types of small GTPases played a role in the intracellular trafficking of MVEs [41-43]. It seems that ESCRTdependent and ESCRT-independent mechanisms both work in formation of exosome, and their functions may depend on the cargoes and the cell type.

\section{The direct pathway of exosome formation}

Apart from the classic pathway of exosome biogenesis, there is a second route of exosome formation which is much more immediate. The erythroleukemia cell lines and $\mathrm{T}$ cells could directly release exosomes from plasma membrane [44-46]. These exosomes formed by the direct pathway are indistinguishable from those by the classic pathway.

In sum, exosome formation is certainly complex, which highlights the heterogeneity of the types of exosomes formed by different cells.

\section{Exosome secretion and uptake}

Upon formed, exosomes pinch off from the plasma membrane and prime them for secretion, including autocrine, paracrine and endocrine [39]. The mechanisms which underlie exosome maturation and release were therefore important. Exosomes have a different release pathway compared to other exosomes, which can influence their functional properties. Exosome uptake and secretion pathway may intersect; resulting in a mixed population of both endogenously produced and recycled exosomes (Fig. 1). The mechanisms and pathways associated with exosome uptake [47], and the specificity of exosome for certain host cell types, add complexity to the biological functions of exosome in intercellular communication.

\section{Secretion}

Recently, it has reported the membrane proteins transfer during direct cell-cell contact [24]. Membrane fusion event need to bear the SNAREs, which known as vesicle or v-SNARE and target or t-SNARE [48]. The phenomenon of membrane fusion may be regulated by tetraspanin complexes. In the viral-cell fusion, tetraspanins may inhibit cell fusion. In the cell-cell fusion such as mononuclear phagocytes, the inhibition by CD9 and CD81 has also been reported. Membrane fusion related with acidic $\mathrm{pH}$ has been a potential mechanism $[49,50]$.

The eukaryotic and prokaryotic cells both release exosome, which are cup-shaped particles enclosed by a phospholipid bilayer [1]. The process of exosome release demands extra steps to sort cargoes into MVBs and ILVs, and additional steps to target MVEs to the membrane and to prime them for secretion [39]. The 
mechanism of exosome release requires their fission from the membrane, and also dependent on the interaction of actin and myosin with a subsequent ATP-dependent contraction [51]. Hence, the activation of small GTP-binding proteins leads the exosome bud off from the plasma membranes [52]. Exosome release is also induced by stimuli, such as stress, which leads to a rise in intracellular calcium and cytoskeleton remodeling [53]. Notably, some exosomes may release via direct outward budding and fission of membrane, analogous to apoptotic blebs.

The process of exosome release may also be subjected to further modulation by Rabs, SNAP and SNARE proteins [54]. Rabs are important regulators of exosome transport between different compartments (Fig. 1). Rab5 and Rab7 play an essential role in delivering cargo to the early endosomes [55]. Rab27a and Rab27b act on the step following MVE transport, which is the docking at membrane to promote fusion [39]. The Ral-1 and addition Rabs, such as Rab11 and Rab35, are involved in the direct or potential regulation of MVE secretion [39]. The activation of ARF6 allows the vesicles to bud off directly from the membranes [56, 57]. The Rab7 and its associated proteins promote the recruitment that targets exosome to lysosomes [58].

\section{Uptake}

Once release, exosomes fuse with the plasma membranes of recipient cells to deliver their contents [59]. Alternatively, exosome surface proteins can engage cell surface receptors on recipient cells to induce intracellular signaling [60-62]. Several uptake mechanisms have been proposed for exosome [63]: endocytosis, membrane fusion, and receptor-ligand mediated interactions (Fig. 1) [54, 64]. After uptake by different mechanisms, exosomes reach MVEs. The probably the most frequent fate is that exosomes target to lysosomes and ultimate lead to the degradation of exosome cargoes [39]. Importantly, this degradative pathway could offer metabolites to the recipient cells [65]. Contents delivered by exosomes can also activate various pathological or physiological responses in the recipient cell after internalization. In addition, the recipient cell can also be itself and generate autocrine responses [66]. Under certain circumstances, exosomes may escape digestion and release their cargoes into the recipient cells [67].

\section{Regulation of exosome production and cargo sorting}

Upon secreted, exosomes deliver their contents to adjacent or distant cells and play a role of regulating of gene expression and modificating of phenotypes and biology $[68,69]$. Thus, the contents of exosome are a critical determining factor in their functions.

\section{Exosome production}

\section{Membrane protein}

The exosomal protein content reflects their origin and varies depending on the types of host cell [70]. All exosomes from varies cell types possess a few common sets of proteins. The most commonly proteins are the classes of membrane transport and fusion proteins, and others such as cytoskeletal, metabolic, signaling, and carrier proteins and albumin [71]. The exosomal protein most frequently are tetraspanins, which including CD63, CD9, CD81, and CD82, ESCRT-I associated protein (such as Tsg101), lysosome-associated membrane glycoproteins (including LAMP-1 and 2B), MVB-associated protein (Alix-1), heat shock proteins (hsp60, 79, and 90), adhesion molecules (CD45 and CD11b), major histocompatibility molecules (MHC-I and II), Rabs, and membrane-binding proteins (annexins) [72]. The ovarian cancers metastasis regulation via MGAT3 mediated glycosylation of tetraspanin CD82 at asparagine 157 [73]. Moreover, exosomes carry diverse enzymes, including GTPase, metabolic enzymes (including peroxidases, pyruvate and lipid kinases, and enolase-1) [74], with all protein content of exosomes that have been found in the cytosol, plasma membrane or in membranes of endocytic origin [70]. These exosomal proteins were not found to consist of proteins of nuclear, mitochondrial, endoplasmicreticulum or Golgi-apparatus origin [70].

\section{Molecular cargo}

The plentiful RNA content could result in the greatest source of signaling diversity. Many researches have demonstrated that mRNAs, miRNAs, and other noncoding RNAs contain in exosome [70]. They can be absorbed when exosome circulate, which ultimate lead to modify the target gene expression, signal, and overall biological function of receipt cells [75]. Exosomal miRNA expression can alter under physiological or pathological conditions. It is known that mRNA was selectively distributed into exosomes, because specific sequences were either preferentially retained or sorted inside the cells [6, 76, 77]. Different extracellular miRNA carriers may transport different miRNA sequences [78, 79]. There are apparently selective mechanisms that control the specific loading of RNA into exosome, and which eventually resulted in that not all mRNAs species present in a cell end up in exosome. It has been shown that a class of miRNAs sequences are preferentially sorted into exosomes, 
such as miR-320 and miR-150 [75]. According to previous study, among small RNAs, the content of miRNA is higher in exosomes than in the host cells [80]. These researches all show that host cells hold a sorting mechanism that guides specific miRNAs into exosomes.

\section{Lipid composition}

Exosomes carry certain lipids, which play an essential role in maintaining the biological activity [37, 81, 82]. Exosomes carry cholesterol, sphingolipids, phosphoglycerides, ceramides, and saturated fatty acid chains [48]. Importantly, in term of lipid, exosomes gain rigidity and maintain their stability, and facilitating the process of internalization [83]. Nevertheless, the lipid content in exosomes does not stand for the host cell [84]. Some lipids also have extra biological functions, such as trafficking, recognition, and internalization [85], however, the lipid content of exosome holds limited data.

\section{Cargo Sorting}

Exosomes are enriched with a unique content of proteins, RNAs, and lipids that can vary from the parent cell. The intraluminal content of the exosomal membrane depends on the host cells, and on their cytoplasmatic composition in particular [86]. And exosomes allow the transfer of plasma membrane and cytoplasmic components that could reprogram recipient cells. Regarding the sorting mechanism of exosomal cargo, exosomes receive cargoes through the ESCRT-dependent and the independent mechanisms (Fig. 2) [87]. In addition, the stress, such as hypoxia, also can change the contants of exosome.

\section{ESCRT-dependent sorting mechanism}

The ESCRT complex has been well acknowledged as a main cargo sorting mechanism. The ubiquitination and ubiquitin-like modifiers represent one of regulatory systems in protein location, stability and function [88]. Recent evidences point that ESCRT family involved in sorting

ESCRT dependent

ESCRT independent

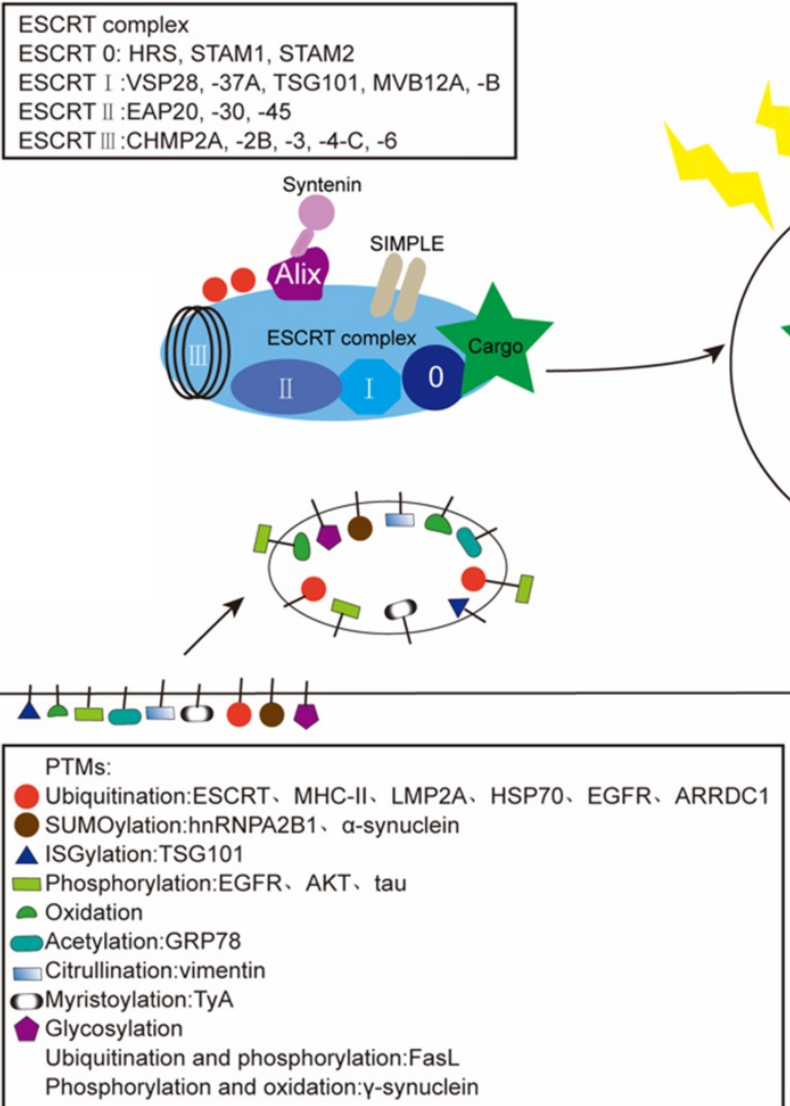

Figure 2. Schematic illustration of exosome sorting. Endosomal sorting complexes required for transport (ESCRT) control the sorting of proteins into exosomes via adding PTMs. Tetraspanins (CD8I, CD9, CD63) play a key role in the composition of ESCRT-independent exosomes. And lipid raft-mediated cargo including different lipids and lipid-related enzimes can be loaded into exosomes by the ESCRT-independent pathway. Mature miRNAs are sorted into exosomes via six potential modes: a) miRNA motif and sumoylated hnRNPs-dependent pathway; b) 3'miRNA sequence-dependent pathway; c) the miRISC-related pathway; d) membrane proteins-dependent pathway (e.g. nSMase2); e) other RNA-binding proteins related pathway (e.g. YB-I); f) other potential pathway (e.g. lipid raft). The stress-induced changes in exosomes can influence the composition of exosomes. 
ubiquitinated proteins into endosome compartments prior to exosome budding and scission (Fig. 2) [89]. ESCRT complex performs three functions: it recognizes ubiquitylated cargoes and prevents their degradation; then, it deforms the membrane and sorting cargo in or out; final, it forms ILVs which contain the sorted cargo [90]. Proteins are usually loaded into exosome with the help of the ESCRT complex. The ESCRT complex is an important element of the machinery that controls the ubiquitinated proteins into ILVs. The ESCRT complex includes four sub-complexes that successively recognize protein cargoes and sorting into ILVs [88]. The ESCRT-I recruited by ESCRT-0 is important to initiat MVB dependent cargoes sorting [91]. ESCRT-0 which contains ubiquitin-binding domains (UBDs), could bind tightly to cargo, or even bind with polyubiquitinated cargo [92]. Besides ubiquitinbinding motifs, ESCRT-0 could engage cargo through the interactions with the clathrin vesicle machinery [91]. The ESCRT-I and ESCRT-II both contain UBDs, while the ESCRT-III subunits hold no UBDs [91]. Here, the ESCRT-I component Tsg101 play a functional role in exosome recruitment of Gal3. Tsg101 can specifically recognizes $\mathrm{P}(\mathrm{S} / \mathrm{T}) \mathrm{AP}$ sequences via an amino-terminal ubiquitin E2 variant (UEV) domain [93]. Nedd4-mediated ubiquitination seems to be an essential process to recruit viral proteins (Gag, LMP2A) [94]. It has been shown that while the content of exosomes are not normally hold Nedd4, Nedd4-2 and Itch, Ndfip1 can recruit all these three Nedd4 proteins into exosomes [95]. The ability of Nedd4 family recognizes the late (L) domaincontaining proteins through the WW domain and the PY motif and sorts into exosomes [96-98]. The BAG6 plays a regulatory role on exosome cargoes loading via association with components of the ESCRT complex [99]. As described, the motif P(S/T)AP of BAG6 to be crucial for the direct association with Tsg101, an interaction mechanism reminiscent to the ESCRT recruitment during virus assembly [99]. Besides binding ubiquitin, the ESCRT complex could be ubiquitinated themselves [88]. The ESCRTdependent mechanism that sorted proteins into ILVs is involved with ubiquitination [91]. Before packaging cargo into ILVs, deubiquitination is mandatory [88]. ESCRT complex hold the ability of sorting ubiquitinated proteins into ILVs [91]. The E3 ubiquitin ligase related with ubiquitin turnover can control the destiny of MVBs. This indicated that deubiquitination is required to sort cargoes into ILVs and exosomes.

However, not all the sorting of proteins depends on ubiquitination. The recent studies show that ubiquitinated proteins can evade deubiquitination. Ubiquitination drives the endocytosis and sorting of MHC II to the luminal vesicles of MVBs for lysosomal degradation [100]. It had proved that for MHC II in antigen-loaded DCs, there is an alternative MVB sorting mechanism, that sorting of MHC II to exosomes occurs independently in MHC II ubiquitination [100]. In addition to ubiquitination, acetylation can abrogate the sorting of proteins into exosomes. Study has shown that this posttranslational modifications (PTMs) serves as a signal for cargo transport into MVBs and demonstrated the ESCRT machinery play a crucial role in this pathway [101]. These proteins in exosomes are modified at the position of certain protein residues and are involved in the regulation of MVBs (Table 1). In summer, deciphering the sophisticated ESCRT-dependent pathway is necessary to unveil specific functions in the selective import of proteins into exosomes.

Table I. PTM proteins sorting into exosomes. The residues were marked in the brackets

\begin{tabular}{ll}
\hline Group & Target Protein(protein residues) \\
\hline Ubiquitination & Histone H1.2; HLA-G complex;ARRDC1-(Lys, N-terminus, non-lysine residues (Cys, Thr, Ser)); LMP2A-(Lys, N-terminus, non-lysine \\
& residues (Cys, Thr, Ser)); PTEN-(Lys, N-terminus, non-lysine residues (Cys, Thr, Ser)); hsp70-(Lys, N-terminus, non-lysine residues (Cys, Thr, \\
& Ser)); SIMPLE-(Lys, N-terminus, non-lysine residues (Cys, Thr, Ser)); Aquaporin-1; Annexin A1; Plastin-3 isoform 1; hspX; GroES; GFP; \\
& ATG85B-ESAT6; nHer2; MHC-II; Tsg101; Hrs Epsin; Rabex; Eps15; Fas Ligand. \\
Phosphorylation & CryAB; Tau; EGFR; IRS-1; PDK1; AKT; SRC; ELK1; ERK 1/2; AMPKa1; Acetyl-CoA carboxylase; NCC; Aquaporin 2; GPRC5C; CHMP2B; \\
& Annexin A2-(Tyr,Thr,Ser,His); tau-(Tyr,Thr,Ser,His); Fas Ligand-(Tyr,Thr,Ser,His); Y-synuclein-(Tyr,Thr,Ser,His). \\
SUMOylation & GFP; a-synuclein; hnRNPA2B1 \\
ISGylation & Tsg101 \\
Oxidation & Y-synuclein \\
Acetylation & GRP78 \\
Citrullination & Vimentin \\
Myristoylation & TyA-(N-terminal glycine residue) \\
Glycosylation & LGALS3BP, CD82-(Asn157) \\
GPI-anchor & CD55 \\
FAT10ylation & FAT10-(carboxyl-terminal GlyGly)
\end{tabular}




\section{ESCRT-independent sorting mechanism}

\section{Protein sorting}

PTMs can direct exosomes loading and specific PTMs can control the selective mechanisms of protein cargo sorting and promote some proteins to enrich in exosomes [87]. In addition to ubiquitination, SUMOylation, ISGylation, phosphorylation, oxidation, citrullination, glycosylation and myristoylation are availabled for regulating exosome loading and interact between various PTMs [102]. Ubiquitination or SUMOylation of proteins worked in sorting into exosomes, while acetylation or ISGylation have an opposed role of driving the modified protein to degradation [103-105]. Oxidation and redox processes play a crucial role in exosome cargo sorting. Importantly, oxidation may also affect lipids of the exosome membrane [106]. De Jong et al. pointed out that stress, such as hypoxia, could alter the composition of cell-derived exosomes [107]. Oxidative stress also influences the RNA composition in exosomes. Of note, recipient cells preconditioned with such exosomes, are protected from oxidative stress, verified the statement from the other side [108]. Many studies show that phosphorylation changes the biogenesis of exosome, including ARF6-GTP (ADP ribosylation factor 6) could regulated cargo sorting [109]. Glycosylation is a kind of PTMs proteins influencing exosome cargo proteins and membrane. Exosomes, from T-cells, melanoma and colon cancer cells as well as biological fluids, were shared similar glycosylation [102]. And as described, adding glycosylating motifs into the specific protein could also mediate its incorporation into exosomes [102, 110]. FAT10, containing a carboxyl-terminal GlyGly motif, could modify its target proteins via FAT10ylation to load to exosomes [111]. In sum, these PTMs work as a disposal mechanism for cellular harmful components or as a repair mechanism in the pathological or physiological conditions through regulating the release and uptake of exosome. However, the role of these other PTMs remains largely unexplored and this could suggest that a role for these PTMs is unlikely work.

\section{Lipid-related sorting}

On the other side, growing evidences indicate that the existence of ESCRT-independent mechanisms also play an essential role, including lipid raft, tetraspanin and ceramide-mediated mechanisms. The ESCRT-dependent and independent pathways were not necessarily contradictory, but rather showed the presence of heterogeneous populations of exosome. It has been found that the pathway for intraendosomal transport of proteolipid protein (PLP) may be independent on ESCRT [37]. The lipid raft domains of the exosomal membrane can sort some proteins into exosomes [112]. Initially, as a mechanism for the selective clearance of clustered membrane receptors and lipids, the lipid rafts involved in exosome sorting was proposed in maturing reticulocytes [113]. A recent article pointed out that lipids may be loaded by lipid rafts [114]. The lipid raft domains also might constitute the platform for loading into ILVs [115]. In addition, in an oligodendrocyte cell line, loading proteolipid protein into exosomes depends on sphingolipid ceramide [37]. Moreover, it was reported that a ceramide-dependent mechanism of membrane invagination allowing formation of internal vesicles and cargo loading [37]. It has been shown that the nature of the transmembrane and/or luminal domains have a strong influencet on protein loading into exosomes [115]. Of note, CD63 induced by ceramide can be blocked by the inhibitor of sphingosine kinase [116]. Protein sorting also involved tetraspanin CD63. Cytosolic domains of proteins or lipid domains enriched in the tetraspanin CD9 or CD63 play a role in loading transemembrane proteins to intraluminal vesicles [117, 118]. It has been observed that CD63 surrounds the MN envelope and sorts nuclear contents in exosomes [119]. It has been demonstrated that CD63 interplays with the RNA binding protein, Y-box protein 1 (YB-1), to sort miR-223 into exosomes, which further supported the mechanism of CD63 in exosome cargo loading [120]. For example, this tetraspanin controls the EBV protein LMP1 entry into exosomes [40], and regulates PMEL sorting into ILVs [121], this process independent of the ESCRT complex and ubiquitination [122]. CD81enriched domains have been proved that could work as sorting platforms for exosomal proteins [123] and account for ESCRT-independent cargo sorting and the formation of ILVs population. Tsg101 [124], Vps4 [125], and ALIX [126] might also be related with the sorting mechanism of proteins or RNAs.

\section{RNA and DNA sorting}

The exosomal RNAs are not random and the RNAs sorting process is highly selective [127, 128]. It has been proved that miRNAs loading in exosomes can be controlled by miRNAs and specific endogenous target sequences [129]. First of all, a class of miRNAs are preferentially loaded into exosomes, such as miR-320 and miR-150 [75]. Based on current research, mechanism of loading for miRNAs summarized as these main pathways and one other potential mechanism [75].

1) The sumoylated heterogeneous nuclear ribonucleoproteins (hnRNPs)-dependent mechanism [75]. The miRNAs sequences in exosomes are 
identified common seed sequences, termed EXOmotifs, that could facilitate binding with RNAbinding proteins, such as hnRNPA2B1 [130] and SYNCRIP [131]. Some studies prove that short sequence motifs overrepresented in miRNAs (EXOmotifs) that control sorting into exosomes and identify that their directed mutagenesis enables modulation of miRNA cargoes (Table 2) [130]. The hnRNPA2B1 specifically binds 30 exosomal miRNAs via recogniting GGAG motifs and loads into exosomes [132]. The exosomal hnRNPA2B1 is sumoylated, and sumoylation guides the binding of hnRNPA2B1into miRNAs [130]. Notably, it is shown that hnRNPA2B1 contains two short RNA recognition motifs (AGG and UAG) in the structure of protein-RNA complex [133]. Study identified the GGAG/UGCA motifs for the interaction between the protein hnRNPA2B1 and two miRNAs, miR-198 and miR-601 [130]. SUMOylation has been shown to control sorting RNA species into exosomes. It has been detected that the SYNCRIP recognized 103 exosomal miRNA sequences, only GGCU is validated [131]. SYNCRIP recognizes a specific sequence (GCUG) at the 3' end of miRNAs for exosome sorting [131]. The finding showed that as a component of the miRNA exosomal sorting machinery, the identification of the RNA-interacting protein SYNCRIP, regulated exosome-enriched miRNAs loading [131]. Moreover, hnRNPA1 was found to mediate miRNAs like miR-522 packing into exosomes [134]. Besides a specific motif (GUUG), it was detected to sort miR-582-5p into exosomes [135]. Study found that the GCAG motif present in the miR-1246 controls exosomal miR-1246 enrichment [136].

2) The $3^{\prime}$-end of the miRNA sequence-dependent pathway [137]. Exosomal mRNAs cargoes, which enriched in 3'UTR fragments, seem to be essential for specific mRNAs loading into exosomes $[138,139]$. The CTGCC motif and the miR-1289 specific sequence are shared by other mRNAs enriched in exosomes [139].

Table 2. The motifs of RNAs sorting into exosomes

\begin{tabular}{|c|c|c|c|c|c|}
\hline Group & & EXO-motif & mRNA & miRNA & $\begin{array}{l}\text { Other noncoding } \\
\text { RNA }\end{array}$ \\
\hline \multirow[t]{10}{*}{ hnRNPs } & hnRNPA2B1 & GGAG & & $\begin{array}{l}\text { miR-654-5p;miR-520e;miR-520b;miR-451;miR-671-5p;m } \\
\text { iR-1226;miR-422a;miR-193b;miR-198;miR-601;miR-1224 } \\
\text {-5p;miR-125b-1;miR-125a-3p;miR-483-5p;miR-583;miR- } \\
\text { 630;miR-513c;miR-513b;miR-513a-5p;miR-188-5p;miR-8 } \\
\text { 87;miR-575;miR-765;miR-134;miR-877;miR-1225-5p;mi } \\
\text { R-638;miR-135a;miR-769-3p;miR-339-3p;miR-939 }\end{array}$ & \\
\hline & & AGG/UAG & & miR-17;miR-93 & \\
\hline & & GGAG/UGCA & & miR-198;miR-601 & \\
\hline & & / & & miR-503 (Negative) & \\
\hline & & & & & $\operatorname{lncARSR}$ \\
\hline & SYNCRIP & GGCU & & $\begin{array}{l}\text { miR-6237;miR-409-3p;miR-6337;miR-692;miR-144-5p;m } \\
\text { iR-369-3p;miR-379-5p;miR-300-3p;miR-410-3p;miR-412 } \\
\text {-5p;miR-127-5p;miR-381-3p;miR-5108;miR-144-3p;miR- } \\
\text { 8095;miR-223-3p;miR-6981-5p;miR-122-5p;miR-493-5p; } \\
\text { 127-3p;miR-3470a;miR-194-2-3p }\end{array}$ & \\
\hline & & GCUG & & & \\
\hline & hnRNPA1 & & & miR-198;miR-522;miR-320;miR-196a & \\
\hline & & GUUG & & miR-582-5p & \\
\hline & & GCAG & & $\operatorname{miR}-1246$ & \\
\hline \multirow[t]{2}{*}{ 3'UTR } & & & & miR-486-5p;miR-143-3p;miR-101-3p & \\
\hline & & CTGCC & & $\operatorname{miR}-1289$ & \\
\hline $\begin{array}{l}\text { miRISC } \\
\text { (Ago2) }\end{array}$ & & & & miR-451;miR--150;miR-142-3p;miR-100;miR-320a;let-7a & \\
\hline \multirow[t]{2}{*}{$\begin{array}{l}\text { Membrane } \\
\text { proteins }\end{array}$} & Vps4A & & & $\begin{array}{l}\text { miR-27b-3p;miR-92a-3p;miR-92a;miR-150;miR-193a-3p; } \\
\text { miR-320a;miR-132-3p }\end{array}$ & \\
\hline & nSMase2 & & & miR-210;miR-16;miR-146a & \\
\hline \multirow{12}{*}{$\begin{array}{l}\text { RNA-binding } \\
\text { proteins }\end{array}$} & YB-1 & ACCAGCCU & pre-mRNA & & \\
\hline & & CAGUGAGC & SEPT14 & & \\
\hline & & UAAUCCCA & & & \\
\hline & & & & $\begin{array}{l}\text { miR-223;miR-133 } \\
\text { miR-144;miR-233 (Negative) }\end{array}$ & \\
\hline & & oligoguanine motif & & & tRNA \\
\hline & NSUN2 & CAGUGAGC & mRNA & & \\
\hline & & & & & lncRNA \\
\hline & MEX3C & & & miR-451a & \\
\hline & Major Vault Protein & & & miR-193a & \\
\hline & La protein & & & miR-122 & \\
\hline & MTR4 & & & & \\
\hline & Anexin-2 & & & & \\
\hline \multirow{2}{*}{$\begin{array}{l}\text { Other } \\
\text { potential } \\
\text { pathway }\end{array}$} & & $\begin{array}{l}3 \text { GCCG,2 UGAC,2 UCCG, } \\
\text { GGAC, GGCG, UGCC }\end{array}$ & $\begin{array}{l}\text { raft-binding sequence } \\
\text { RNA } 67-2\end{array}$ & & \\
\hline & & $\begin{array}{l}3 \text { GCCG, } 2 \text { UGAC, } 2 \text { UGCC, } \\
\text { GGAC, GGCG, CCCG, GGCC }\end{array}$ & $\begin{array}{l}\text { raft-binding sequence } \\
\text { RNA } 10\end{array}$ & & \\
\hline
\end{tabular}


3) The miRNA induced silencing complex (miRISC)-related pathway [140]. Ago2 has been reported to exert some specific control over the sorting of let-7a, miR-100, and miR-320a into exosomes [141].

4) Membrane proteins related pathway. Membrane proteins like Vps4A and nSMase2 are worked in the miRNA sorting into exosomes. A ceramide-dependent secretory machinery could release some exosomal miRNAs and this process is independent on the ESCRT system [142]. Of note, overexpressing nSMase 2 could increase the levels of miR-16 and miR-146a in exosomes, while hold no effect on cellular miRNA levels [142]. The circRNAs in exosomes are shown to maintain biological activity and can abrogate the growth inhibition induced by miR-7 in recipient cells [143]. Overexpressing Vps4A resulted in increasing levels of exosomal miR-27b-3p and miR-92a-3p in hepatocellular carcinoma cells (HCC), and also caused higher levels of exosomederived miR-193a-3p, miR-320a, and miR-132-3p [125]. On the other side, inhibition of Vps4A resulted in lower levels of exosomal miR-92a and miR-150 [144].

5) Other RNA-binding proteins related pathway. The studies proved that specific proteins may control miRNA sorting through recognizing and binding to specific RNAs sequences [131]. YB-1 has been demonstrated that it is responsible for the sorting miRNAs and mRNAs into exosomes [120, 145]. It has considered that YB-1 could recognize and bind specific mRNA motifs, such as ACCAGCCU, CAGUGAGC and UAAUCCCA [146, 147], and exosomal long ncRNAs (lncRNAs), and control specific lncRNA sorting into exosomes [148]. It has proved that YB-1 and NSUN2 as the only proteins interplaying with eRNA-specific motifs, and YB-1 specifically interplays with all three motifs, while NSUN2 only recognizes the motif CAGUGAGC [146, 148]. Mutation of YB-1 was identified to impair the sorting miR-144 and miR-223 to exosomes [120, 145, 149]. A recent research showed that the cleavage of tRNAs induced by cellular stress causes the production of a class of tRNA fragments containing an oligoguanine motif, which binds YB-1 in a sequence-specific manner [150]. And 18 lncRNAs by NSUN2 were associated with exosomes [151]. Besides YB-1 and NSUN2, other RNA-binding proteins like MEX3C, Major Vault Protein 4(MVP4), La protein, MTR4 and Anexin-2 work as a key role in exosome cargo sorting [152]. MEX3C works as an RNA-binding E3 ubiquitin ligase to mediate mRNA degradation and the MEX3C-Ago2 complex could sort miR-451a into exosomes [153]. Collectively, miR-193a is shuttled into exosomes by an MVP-dependent process [154].
The La protein is an RNA-binding protein that functions as shuttling miR-122 into exosomes [155]. Nuclear exosome adaptors have evolved canonical and non-canonical AIM sequences to target human MTR4 and prove the versatility and specificity with which the MTR4 arch domain can recruit a repertoire of different RNA-binding proteins [73, 156]. Anexin-2 might work in sorting RNAs into exosomes, since it binds specific RNAs [157-159] and it is highly enriched in exosomes [160].

6) Other potential pathway. Another ESCRTindependent mechanism may depend on raft-based microdomains for the lateral segregation of cargoes [37]. This exosome packaging process depends on a lipid-bilayer binding motif within the specific RNA sequences [161]. Ten EXO-motifs (three GCCG, two UGAC, two UCCG, GGAC, GGCG, UGCC) exist in the raft-binding sequence RNA 67-2. Another subset of eleven EXO motifs (three GCCG, two UGAC, two UGCC, GGAC, GGCG, CCCG, GGCC,) is discovered in another raft-binding sequence, RNA 10[161, 162]. Of note, overexpressing miR-1289 increases the sorting GalR3 mRNA into exosomes, suggesting that miRNAs could selectively package RNA cargoes into exosomes [87].

As RNA and DNA sorting is still a relatively novel field, it is possible that the current literature only represents studies that have positive findings. Additionally, RNA and DNA sorting is a complicated phenomenon and it is diffcult determine whether the sorting proteins are part of independent sorting mechanisms or whether they involved in a unified larger sorting mechanism.

\section{Exosome-based strategies for diagnosis and therapy}

Exosomes exist in all biological fluids and are secreted by all kinds of cells, making them attractive as minimally invasive liquid biopsies with the potential for sampling to follow disease progression [31]. Of note, exosomes reflect the metabolic status of the host cells, which mirrors the emerging role of exosome as a fingerprint in the disease diagnosis [163, 164]. Studies show that exosomes work as a mechanism similar to that of viruses for coming into cells. Because of viral-like transfection efficiency and inherent biological functions, accumulating evidence reports that exosomes can work as novel delivery platforms for therapy [165]. This twin modality of therapeutic and diagnostic is termed theranostics in the emerging field of nanomedicine [165]. The long-range targeting and tissue uptake of exosome and their stability in the circulation or in other biological fluids render exosome attractive as a 
biomarker and a therapeutic vehicle in diseases application (Fig. 3).

\section{Diagnosis}

Given their presence in most bodily fluids, exosomes have been wildly known as potential biomarkers for many diseases [166]. Cancer cellderived exosomal miRNAs are different from nonmalignant cells, and such exosomes can be sentinels of disease. Hence, it is theoretically possible to "harvest" these exosomal RNAs, which could provide unique signatures of its host cell, for diagnostic purposes [165]. It is observed that serum exosomal miR-223 is a promising biomarker for diagnosing dementia [167]. It proved that serum exosomal HOTAIR can be served as a novel prognostic and diagnostic biomarker for glioblastoma multiforme [168]. Besides the molecular cargo, exosomal proteins and lipids are also reported as biomarkers. A recent study considered that surviving (an oncoprotein associated with chemoresistance) is overexpressed in patient serum-derived exosomes and works as a diagnostic and prognostic biomarker of prostate cancer (PCa) [169]. Tore Skotland et al. showed that lipids in exosomes are promising prostate cancer biomarkers [170]. Thus, exosomes have been worked as a potential marker for prediagnosis of diseases by monitoring exosomal contents in the biological fluids. Exosomes can be useful for early diagnosis, targeted therapy, prognosis and clinical monitoring. And exosome diagnosis has a variety of advantages of diagnosis, such as minimally-invasive tissue collection and enrichment in specific exosomal biomarkers. However, the lack of enrichment and time-consuming and expensive identification process still remain a challenge for the clinical application of exosomes.

\section{Therapy}

As the function of exosome cargo has become more widely recognized, exosomes have been proposed as a potential alternative to cell-based therapies. The multifaceted nature of exosome and their compositions underscores the advantage of exosome therapy [171]. Exosomes carrying RNAs, miRNAs, or proteins, may be an essential mechanism and the vehicle of their action to reduce inflammation, mediate cellular signaling, and cause tissue repair [172]. Compared with exogenous engineering exosomes, the therapeutic effect of endogenous exosomes is limited. Engineering exosomes are promising materials for the next generation of
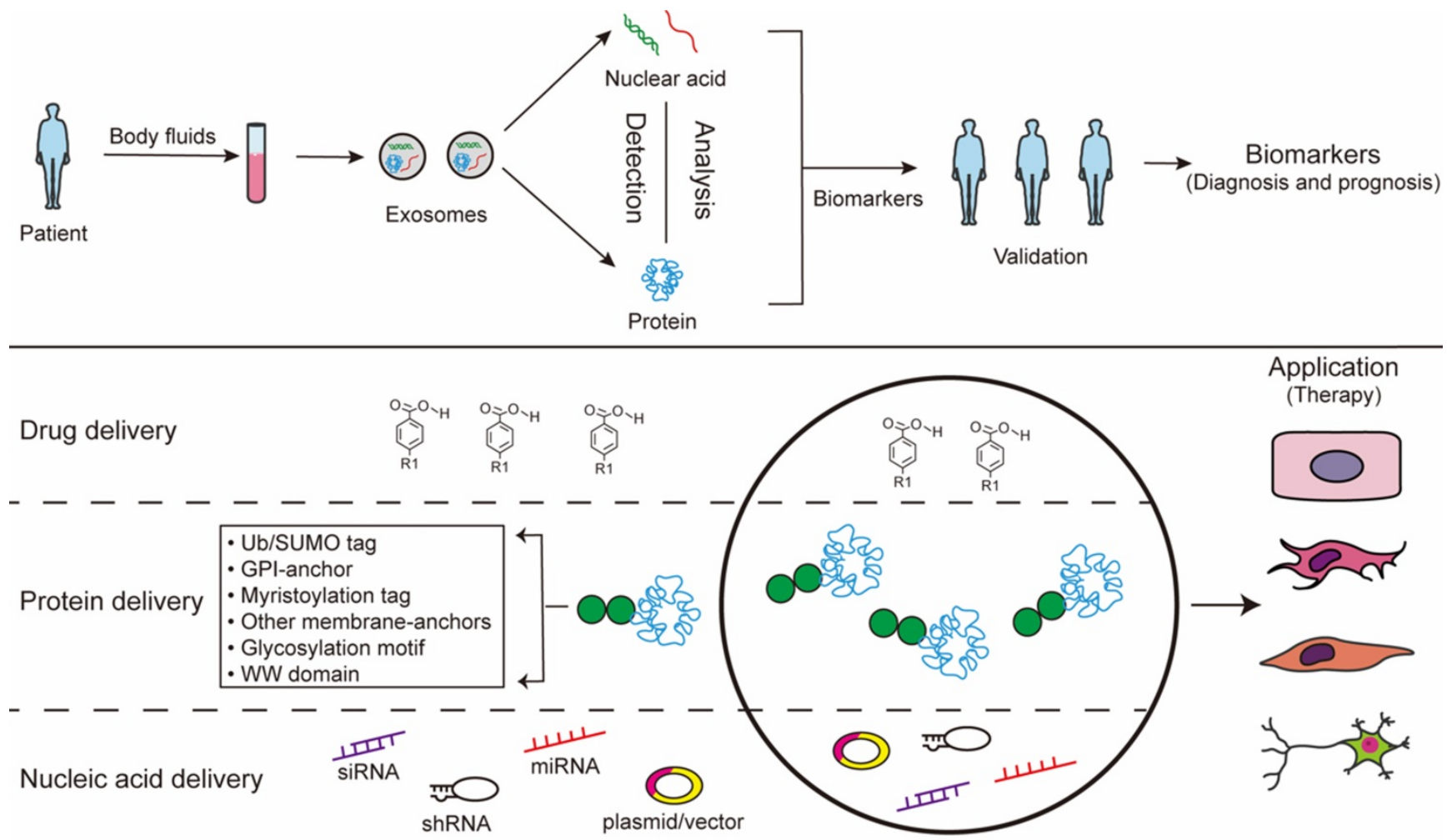

Engineering exosomes

Recipient cells

Figure 3. Exosomes for biomedical application. The contants of exosomes obtained from body fluids can be analysed to identify certain condition biomarkers for disease prognosis and diagnosis. Additionally, the exosomes can be modified to contain specific cargoes through bioengineering of exosomes: I) exosomes can be loaded with chemical drugs for carrier-assisted delivery; 2) exosomes can be targeted by the addition of a specific PTM motif for engineered therapeutic proteins; 3 ) small interference RNAs can be performed to incorporate inside exosomes therapeutic. 
nanomedicine for therapy with non-cytotoxic effects and low immunogenic profiles [173]. Engineering exosomes can be packaged with different cargoes, including drugs, recombinant proteins, and nucleic acids like miRNAs, siRNAs. They hold numerous positive attributes that are pivotal in their function as therapy exosome [174]. Firstly, exosomes have many features of an ideal drug delivery exosomes. Exosomes containing therapeutic cargo could be generated by sorting exogenous cargo into cells or by directly sorting cargo into exosomes. Drug delivery technology is taking advantage of exosomes as vehicles to overcome biological barriers [175]. Exosomes passively loaded with curcumin provide protection against lipopolysaccharide (LPS)-induced microglial activation that causes brain inflammation [176]. It is well known that MSC serve as a cost effective exosomes producer for drug delivery. Exosomes derived from MSCs recapitulate the cytoprotective activities and immunomodulatory of their host cells [177]. MSC-derived exosomes have been demonstrated in various diseases models, such as respiratory, cardiovascular, neurological, musculoskeletal, hepatic, gastrointestinal, dermatological, and renal disease [178]. Secondly, proteins and genetic materials indicate that such biological materials could be packaged into exosomes. Modifications of exosome cargo can confer additional benefits, such as enhanced effects and targeting capability to exosomes. However, the direct sorting of nucleic acids into exosomes may not deliver functionally active cargo into recipient cells efficiently. Thus, RNAs or proteins passively sorted into exosomes by lipofection without cellular cargo loading regulation might be less favorable than RNAs or proteins loaded into naturally occurring or preconditioned cell-derived naive exosomes. The exosome-containing PTM proteins, which called engineered exosomes, enhance their potential as therapeutic tools via selective delivery of therapeutic components into specific tissues. The uptake of exosome containing the $\mathrm{C}-\mathrm{t}$ domain of PTEN by cancer cells reduces proliferation, migration and metastasis, postulating such a strategy as an anti-tumor treatment [179]. The delivery of interfering RNAs is the treatment of different types of cancers, due to the disease-related dysregulation of numerous mRNAs [180, 181]. It may be possible to add motifs to RNA in the future so that therapeutic RNA can be better sorted into exosomes to achieve therapeutic effects. Thirdly, liposomes could deliver cargoes shuttle the membrane and provide a barrier against premature transformation and elimination [182]. And they are also amenable to in vivo and in vitro package therapeutic agents, and membrane modifications to enhance tissue-specific homing [182]. Fourthly, exosomes are well tolerated as evidenced by their wide distribution in biological fluids [183]. Exosomes have an intrinsic ability to home to target tissues, which made the effects of exosomes targeted therapy significantly improved [182] and exosomes have been shown to cross the plasma membrane to deliver their cargo into target cells. Exosomes can be engineered to overexpress specific miRNAs or carrying specific siRNAs that are incorporated into the exosomal cargoes and delivered in vivo for the specific targeting of disease. Specially, exosomes have a protective effect on craniocerebral diseases. They have ability to accross the blood-brain barrier, and enhance neural and motor function, which opens a wide variety of possibilities for treatment of neurodegenerative diseases [24]. The cargo sorting mechanisms confer specific properties to proteins and RNA, hence, the use of exosome sorting mechanisms represents a tremendous potential tool for the generation of therapeutically personalized and engineering exosomes. Through the study of the exosome sorting mechanisms, nucleic acids and proteins enrichment on engineered exosomes may be used target exosomes to specific cell types and achieve the highconcentration impact targeted therapy. However, the application of exosomes is difficult because of a number of unresolved issues, such as the efficiency of exosome engineering, cost-effectiveness, safety, and biodistribution/pharmacokinetics [184].

\section{Acknowledgements}

The author wants to acknowledge the Natural Science Foundation of China (grant no. 81672913/81871343), the Social Development Project of Jiangsu (grant no. BE2018693/BE2017698), Natural Science Foundation of Jiangsu Province (grant no. BK20181226), the Jiangsu Provincial Medical Youth Talent (QNRC2016460, FRC201788), Medical research project of Jiangsu Commission of health (H2019055).

\section{Competing Interests}

The authors have declared that no competing interest exists.

\section{References}

1. van der Pol E, Boing AN, Harrison P, Sturk A, Nieuwland R. Classification, functions, and clinical relevance of extracellular vesicles. Pharmacol Rev. 2012; 64: 676-705.

2. Raposo G, Stoorvogel W. Extracellular vesicles: exosomes, microvesicles, and friends. J Cell Biol. 2013; 200: 373-83.

3. Johnstone RM, Adam M, Hammond JR, Orr L, Turbide C. Vesicle formation during reticulocyte maturation. Association of plasma membrane activities with released vesicles (exosomes). J Biol Chem. 1987; 262: 9412-20.

4. Batista BS, Eng WS, Pilobello KT, Hendricks-Munoz KD, Mahal LK. Identification of a conserved glycan signature for microvesicles. J Proteome Res. 2011; 10: 4624-33.

5. Kahlert C, Melo SA, Protopopov A, Tang J, Seth S, Koch M, et al. Identification of double-stranded genomic DNA spanning all chromosomes with mutated KRAS and p53 DNA in the serum exosomes of patients with pancreatic cancer. J Biol Chem. 2014; 289: 3869-75. 
6. Valadi $\mathrm{H}$, Ekstrom $\mathrm{K}$, Bossios A, Sjostrand $\mathrm{M}$, Lee JJ, Lotvall JO. Exosome-mediated transfer of mRNAs and microRNAs is a novel mechanism of genetic exchange between cells. Nat Cell Biol. 2007; 9: 654-9.

7. Balaj L, Lessard R, Dai L, Cho YJ, Pomeroy SL, Breakefield XO, et al. Tumour microvesicles contain retrotransposon elements and amplified oncogene sequences. Nat Commun. 2011; 2: 180.

8. Saber SH, Ali HEA, Gaballa R, Gaballah M, Ali HI, Zerfaoui M, et al. Exosomes are the Driving Force in Preparing the Soil for the Metastatic Seeds: Lessons from the Prostate Cancer. Cells. 2020; 9.

9. Kogure $\mathrm{T}$, Lin $\mathrm{WL}$, Yan IK, Braconi $\mathrm{C}$, Patel $\mathrm{T}$. Intercellular nanovesicle-mediated microRNA transfer: a mechanism of environmental modulation of hepatocellular cancer cell growth. Hepatology. 2011; 54: 1237-48.

10. Thery C, Amigorena S, Raposo G, Clayton A. Isolation and characterization of exosomes from cell culture supernatants and biological fluids. Curr Protoc Cell Biol. 2006; Chapter 3: Unit 322.

11. Raposo G, Nijman HW, Stoorvogel W, Liejendekker R, Harding CV, Melief CI, et al. B lymphocytes secrete antigen-presenting vesicles. J Exp Med. 1996; 183: 1161-72.

12. Quintana JF, Makepeace BL, Babayan SA, Ivens A, Pfarr KM, Blaxter M, et al. Extracellular Onchocerca-derived small RNAs in host nodules and blood. Parasit Vectors. 2015; 8: 58.

13. Xu R, Greening DW, Zhu HJ, Takahashi N, Simpson RJ. Extracellular vesicle isolation and characterization: toward clinical application. J Clin Invest. 2016; 126: 1152-62.

14. Momen-Heravi F, Balaj L, Alian S, Trachtenberg AJ, Hochberg FH, Skog J, et al. Impact of biofluid viscosity on size and sedimentation efficiency of the isolated microvesicles. Front Physiol. 2012; 3: 162.

15. Zeringer E, Barta T, Li M, Vlassov AV. Strategies for isolation of exosomes. Cold Spring Harb Protoc. 2015; 2015: 319-23.

16. Li P, Kaslan M, Lee SH, Yao J, Gao Z. Progress in Exosome Isolation Techniques. Theranostics. 2017; 7: 789-804.

17. Tauro BJ, Greening DW, Mathias RA, Ji H, Mathivanan S, Scott AM, et al. Comparison of ultracentrifugation, density gradient separation, and immunoaffinity capture methods for isolating human colon cancer cell line LIM1863-derived exosomes. Methods. 2012; 56: 293-304.

18. Grasso L, Wyss R, Weidenauer L, Thampi A, Demurtas D, Prudent M, et al. Molecular screening of cancer-derived exosomes by surface plasmon resonance spectroscopy. Anal Bioanal Chem. 2015; 407: 5425-32.

19. Chen C, Skog J, Hsu CH, Lessard RT, Balaj L, Wurdinger T, et al. Microfluidic isolation and transcriptome analysis of serum microvesicles. Lab Chip. 2010; 10: $505-11$

20. Wang Z, Wu HJ, Fine D, Schmulen J, Hu Y, Godin B, et al. Ciliated micropillars for the microfluidic-based isolation of nanoscale lipid vesicles. Lab Chip. 2013; 13: 2879-82.

21. Erdbrugger U, Lannigan J. Analytical challenges of extracellular vesicle detection: A comparison of different techniques. Cytometry A. 2016; 89: $123-34$

22. Webber J, Clayton A. How pure are your vesicles? J Extracell Vesicles. 2013; 2.

23. Smith ZJ, Lee C, Rojalin T, Carney RP, Hazari S, Knudson A, et al. Single exosome study reveals subpopulations distributed among cell lines with variability related to membrane content. J Extracell Vesicles. 2015; 4: 28533.

24. Gurunathan S, Kang MH, Jeyaraj M, Qasim M, Kim JH. Review of the Isolation, Characterization, Biological Function, and Multifarious Therapeutic Approaches of Exosomes. Cells. 2019; 8

25. Gercel-Taylor C, Atay S, Tullis RH, Kesimer M, Taylor DD. Nanoparticle analysis of circulating cell-derived vesicles in ovarian cancer patients. Anal Biochem. 2012; 428: 44-53.

26. Anderson W, Lane R, Korbie D, Trau M. Observations of Tunable Resistive Pulse Sensing for Exosome Analysis: Improving System Sensitivity and Stability. Langmuir. 2015; 31: 6577-87.

27. Carmicheal J, Hayashi C, Huang X, Liu L, Lu Y, Krasnoslobodtsev A, et al. Label-free characterization of exosome via surface enhanced Raman spectroscopy for the early detection of pancreatic cancer. Nanomedicine. 2019; 16: 88-96.

28. Haque MH, Gopalan V, Yadav S, Islam MN, Eftekhari E, Li Q, et al. Detection of regional DNA methylation using DNA-graphene affinity interactions. Biosens Bioelectron. 2017; 87: 615-21.

29. Lin $M$, Song $P$, Zhou G, Zuo X, Aldalbahi A, Lou X et al. Electrochemical detection of nucleic acids, proteins, small molecules and cells using a DNA-nanostructure-based universal biosensing platform. Nat Protoc. 2016; 11: 1244-63.

30. Sackmann EK, Fulton AL, Beebe DJ. The present and future role of microfluidics in biomedical research. Nature. 2014; 507: 181-9.

31. Kalluri R, LeBleu VS. The biology, function, and biomedical applications of exosomes. Science. 2020; 367.

32. Hanson PI, Cashikar A. Multivesicular body morphogenesis. Annu Rev Cell Dev Biol. 2012; 28: 337-62.

33. Hurley JH. ESCRTs are everywhere. EMBO J. 2015; 34: 2398-407.

34. Colombo M, Moita C, van Niel G, Kowal J, Vigneron J, Benaroch P, et al. Analysis of ESCRT functions in exosome biogenesis, composition and secretion highlights the heterogeneity of extracellular vesicles. J Cell Sci. 2013; 126: 5553-65.
35. Baietti MF, Zhang Z, Mortier E, Melchior A, Degeest G, Geeraerts A, et al Syndecan-syntenin-ALIX regulates the biogenesis of exosomes. Nat Cell Biol. 2012; 14: 677-85.

36. Scott CC, Gruenberg J. Ion flux and the function of endosomes and lysosomes: $\mathrm{pH}$ is just the start: the flux of ions across endosomal membranes influences endosome function not only through regulation of the luminal $\mathrm{pH}$. Bioessays. 2011; 33: 103-10

37. Trajkovic K, Hsu C, Chiantia S, Rajendran L, Wenzel D, Wieland F, et al. Ceramide triggers budding of exosome vesicles into multivesicular endosomes. Science. 2008; 319: 1244-7.

38. Marsh M, van Meer G. Cell biology. No ESCRTs for exosomes. Science. 2008; 319: 1191-2

39. van Niel G, D'Angelo G, Raposo G. Shedding light on the cell biology of extracellular vesicles. Nat Rev Mol Cell Biol. 2018; 19: 213-28.

40. Verweij FJ, van Eijndhoven MA, Hopmans ES, Vendrig T, Wurdinger T, Cahir-McFarland E, et al. LMP1 association with CD63 in endosomes and secretion via exosomes limits constitutive NF-kappaB activation. EMBO J. 2011; 30: 2115-29.

41. Hsu C, Morohashi Y, Yoshimura S, Manrique-Hoyos N, Jung S, Lauterbach MA, et al. Regulation of exosome secretion by Rab35 and its GTPase-activating proteins TBC1D10A-C. J Cell Biol. 2010; 189: 223-32.

42. Ostrowski M, Carmo NB, Krumeich S, Fanget I, Raposo G, Savina A, et al. Rab27a and Rab27b control different steps of the exosome secretion pathway. Nat Cell Biol. 2010; 12: 19-30; sup pp 1-13.

43. Savina A, Fader CM, Damiani MT, Colombo MI. Rab11 promotes docking and fusion of multivesicular bodies in a calcium-dependent manner. Traffic. 2005; 6: 131-43.

44. Booth AM, Fang Y, Fallon JK, Yang JM, Hildreth JE, Gould SJ. Exosomes and HIV Gag bud from endosome-like domains of the T cell plasma membrane. J Cell Biol. 2006; 172: 923-35.

45. Fang $Y$, Wu N, Gan X, Yan W, Morrell JC, Gould SJ. Higher-order oligomerization targets plasma membrane proteins and HIV gag to exosomes. PLoS Biol. 2007; 5: e158.

46. Lenassi M, Cagney G, Liao M, Vaupotic T, Bartholomeeusen K, Cheng Y, et al. HIV Nef is secreted in exosomes and triggers apoptosis in bystander CD4+ T cells. Traffic. 2010; 11: 110-22.

47. Mathieu M, Martin-Jaular L, Lavieu G, Thery C. Specificities of secretion and uptake of exosomes and other extracellular vesicles for cell-to-cell communication. Nat Cell Biol. 2019; 21: 9-17.

48. Thery C, Zitvogel L, Amigorena S. Exosomes: composition, biogenesis and function. Nat Rev Immunol. 2002; 2: 569-79.

49. Parolini I, Federici C, Raggi C, Lugini L, Palleschi S, De Milito A, et al. Microenvironmental $\mathrm{pH}$ is a key factor for exosome traffic in tumor cells. J Biol Chem. 2009; 284: 34211-22.

50. Montecalvo A, Larregina AT, Shufesky WJ, Stolz DB, Sullivan ML, Karlsson $\mathrm{JM}$, et al. Mechanism of transfer of functional microRNAs between mouse dendritic cells via exosomes. Blood. 2012; 119: 756-66.

51. D'Souza-Schorey C, Clancy JW. Tumor-derived microvesicles: shedding light on novel microenvironment modulators and prospective cancer biomarkers. Genes Dev. 2012; 26: 1287-99.

52. Vidal MJ, Stahl PD. The small GTP-binding proteins Rab4 and ARF are associated with released exosomes during reticulocyte maturation. Eur J Cell Biol. 1993; 60: 261-7.

53. Pasquet JM, Dachary-Prigent J, Nurden AT. Calcium influx is a determining factor of calpain activation and microparticle formation in platelets. Eur J Biochem. 1996; 239: 647-54.

54. McKelvey KJ, Powell KL, Ashton AW, Morris JM, McCracken SA. Exosomes: Mechanisms of Uptake. J Circ Biomark. 2015; 4: 7 .

55. Hutagalung AH, Novick PJ. Role of Rab GTPases in membrane traffic and cell physiology. Physiol Rev. 2011; 91: 119-49.

56. Schlienger S, Campbell S, Claing A. ARF1 regulates the Rho/MLC pathway to control EGF-dependent breast cancer cell invasion. Mol Biol Cell. 2014; 25: 17-29.

57. Sedgwick AE, Clancy JW, Olivia Balmert M, D'Souza-Schorey C. Extracellular microvesicles and invadopodia mediate non-overlapping modes of tumor cell invasion. Sci Rep. 2015; 5: 14748.

58. Rocha N, Kuijl C, van der Kant R, Janssen L, Houben D, Janssen H, et al. Cholesterol sensor ORP1L contacts the ER protein VAP to control Rab7-RILP-p150 Glued and late endosome positioning. J Cell Biol. 2009; 185: 1209-25.

59. Nanbo A, Kawanishi E, Yoshida R, Yoshiyama H. Exosomes derived from Epstein-Barr virus-infected cells are internalized via caveola-dependent endocytosis and promote phenotypic modulation in target cells. J Virol. 2013; 87: 10334-47

60. Colombo M, Raposo G, Thery C. Biogenesis, secretion, and intercellular interactions of exosomes and other extracellular vesicles. Annu Rev Cell Dev Biol. 2014; 30: 255-89.

61. Zhang X, Yuan X, Shi H, Wu L, Qian H, Xu W. Exosomes in cancer: small particle, big player. J Hematol Oncol. 2015; 8: 83.

62. Mincheva-Nilsson L, Baranov V. Cancer exosomes and NKG2D receptor-ligand interactions: impairing NKG2D-mediated cytotoxicity and anti-tumour immune surveillance. Semin Cancer Biol. 2014; 28: 24-30.

63. S ELA, Mager I, Breakefield XO, Wood MJ. Extracellular vesicles: biology and emerging therapeutic opportunities. Nat Rev Drug Discov. 2013; 12: 347-57. 
64. Emanueli C, Shearn AI, Angelini GD, Sahoo S. Exosomes and exosomal miRNAs in cardiovascular protection and repair. Vascul Pharmacol. 2015; 71: 24-30.

65. Zhao H, Yang L, Baddour J, Achreja A, Bernard V, Moss T, et al. Tumor microenvironment derived exosomes pleiotropically modulate cancer cell metabolism. Elife. 2016; 5: e10250

66. Matsumoto A, Takahashi $\mathrm{Y}$, Nishikawa M, Sano $\mathrm{K}$, Morishita M, Charoenviriyakul C, et al. Accelerated growth of B16BL6 tumor in mice through efficient uptake of their own exosomes by B16BL6 cells. Cancer Sci. 2017; 108: 1803-10.

67. Bissig C, Gruenberg J. ALIX and the multivesicular endosome: ALIX in Wonderland. Trends Cell Biol. 2014; 24: 19-25.

68. Barres C, Blanc L, Bette-Bobillo P, Andre S, Mamoun R, Gabius HJ, et al. Galectin-5 is bound onto the surface of rat reticulocyte exosomes and modulates vesicle uptake by macrophages. Blood. 2010; 115: 696-705.

69. Tian T, Wang Y, Wang H, Zhu Z, Xiao Z. Visualizing of the cellular uptake and intracellular trafficking of exosomes by live-cell microscopy. J Cell Biochem. 2010; 111: 488-96.

70. Boriachek K, Islam MN, Moller A, Salomon C, Nguyen NT, Hossain MSA, et al. Biological Functions and Current Advances in Isolation and Detection Strategies for Exosome Nanovesicles. Small. 2018; 14

71. Ibrahim A, Marban E. Exosomes: Fundamental Biology and Roles in Cardiovascular Physiology. Annu Rev Physiol. 2016; 78: 67-83.

72. Liu C, Su C. Design strategies and application progress of therapeutic exosomes. Theranostics. 2019; 9: 1015-28.

73. Li J, Xu J, Li L, Ianni A, Kumari P, Liu S, et al. MGAT3-mediated glycosylation of tetraspanin CD82 at asparagine 157 suppresses ovarian cancer metastasis by inhibiting the integrin signaling pathway. Theranostics. 2020; 10: 6467-82.

74. Mathivanan S, Fahner CJ, Reid GE, Simpson RJ. ExoCarta 2012: database of exosomal proteins, RNA and lipids. Nucleic Acids Res. 2012; 40: D1241-4.

75. Zhang J, Li S, Li L, Li M, Guo C, Yao J, et al. Exosome and exosomal microRNA: trafficking, sorting, and function. Genomics Proteomics Bioinformatics. 2015; 13: 17-24.

76. Ratajczak J, Miekus K, Kucia M, Zhang J, Reca R, Dvorak P, et al. Embryonic stem cell-derived microvesicles reprogram hematopoietic progenitors: evidence for horizontal transfer of mRNA and protein delivery. Leukemia. 2006; 20: 847-56.

77. Skog J, Wurdinger T, van Rijn S, Meijer DH, Gainche L, Sena-Esteves M, et al. Glioblastoma microvesicles transport RNA and proteins that promote tumour growth and provide diagnostic biomarkers. Nat Cell Biol. 2008; 10: 1470-6.

78. Palma J, Yaddanapudi SC, Pigati L, Havens MA, Jeong S, Weiner GA, et al. MicroRNAs are exported from malignant cells in customized particles. Nucleic Acids Res. 2012; 40: 9125-38.

79. Wang K, Zhang S, Weber J, Baxter D, Galas DJ. Export of microRNAs and microRNA-protective protein by mammalian cells. Nucleic Acids Res. 2010; 38: 7248-59.

80. Goldie BJ, Dun MD, Lin M, Smith ND, Verrills NM, Dayas CV, et al. Activity-associated miRNA are packaged in Map1b-enriched exosomes released from depolarized neurons. Nucleic Acids Res. 2014; 42: 9195-208.

81. Subra C, Laulagnier K, Perret B, Record M. Exosome lipidomics unravels lipid sorting at the level of multivesicular bodies. Biochimie. 2007; 89: 205-12.

82. Wubbolts R, Leckie RS, Veenhuizen PT, Schwarzmann G, Mobius W, Hoernschemeyer J, et al. Proteomic and biochemical analyses of human B cell-derived exosomes. Potential implications for their function and multivesicular body formation. J Biol Chem. 2003; 278: 10963-72.

83. Record M, Carayon K, Poirot M, Silvente-Poirot S. Exosomes as new vesicular lipid transporters involved in cell-cell communication and various pathophysiologies. Biochim Biophys Acta. 2014; 1841: 108-20.

84. Laulagnier K, Motta C, Hamdi S, Roy S, Fauvelle F, Pageaux JF, et al. Mast celland dendritic cell-derived exosomes display a specific lipid composition and an unusual membrane organization. Biochem J. 2004; 380: 161-71.

85. Subra C, Grand D, Laulagnier K, Stella A, Lambeau G, Paillasse M, et al. Exosomes account for vesicle-mediated transcellular transport of activatable phospholipases and prostaglandins. J Lipid Res. 2010; 51: 2105-20.

86. Farooqi AA, Desai NN, Qureshi MZ, Librelotto DRN, Gasparri ML, Bishayee A, et al. Exosome biogenesis, bioactivities and functions as new delivery systems of natural compounds. Biotechnol Adv. 2018; 36: 328-34.

87. Villarroya-Beltri C, Baixauli F, Gutierrez-Vazquez C, Sanchez-Madrid F, Mittelbrunn M. Sorting it out: regulation of exosome loading. Semin Cancer Biol. 2014; 28: 3-13.

88. Moreno-Gonzalo O, Fernandez-Delgado I, Sanchez-Madrid F. Posttranslational add-ons mark the path in exosomal protein sorting. Cell Mol Life Sci. 2018; 75: 1-19.

89. Urbe S, Sachse M, Row PE, Preisinger C, Barr FA, Strous G, et al. The UIM domain of Hrs couples receptor sorting to vesicle formation. J Cell Sci. 2003; 116: 4169-79.

90. Raiborg C, Stenmark H. The ESCRT machinery in endosomal sorting of ubiquitylated membrane proteins. Nature. 2009; 458: 445-52.

91. Henne WM, Buchkovich NJ, Emr SD. The ESCRT pathway. Dev Cell. 2011; 21: 77-91.

92. Ren X, Hurley JH. VHS domains of ESCRT-0 cooperate in high-avidity binding to polyubiquitinated cargo. EMBO J. 2010; 29: 1045-54.

93. Pornillos O, Alam SL, Rich RL, Myszka DG, Davis DR, Sundquist WI. Structure and functional interactions of the Tsg101 UEV domain. EMBO J. 2002; 21: 2397-406.
94. Blot V, Perugi F, Gay B, Prevost MC, Briant L, Tangy F, et al. Nedd4.1-mediated ubiquitination and subsequent recruitment of Tsg101 ensure HTLV-1 Gag trafficking towards the multivesicular body pathway prior to virus budding. J Cell Sci. 2004; 117: 2357-67.

95. Putz U, Howitt J, Lackovic J, Foot N, Kumar S, Silke J, et al. Nedd4 familyinteracting protein 1 (Ndfip1) is required for the exosomal secretion of Nedd4 family proteins. J Biol Chem. 2008; 283: 32621-7.

96. Sette P, Jadwin JA, Dussupt V, Bello NF, Bouamr F. The ESCRT-associated protein Alix recruits the ubiquitin ligase Nedd4-1 to facilitate HIV-1 release through the LYPXnL L domain motif. J Virol. 2010; 84: 8181-92.

97. Staub O, Dho S, Henry P, Correa J, Ishikawa T, McGlade J, et al. WW domains of Nedd4 bind to the proline-rich PY motifs in the epithelial $\mathrm{Na}+$ channel deleted in Liddle's syndrome. EMBO J. 1996; 15: 2371-80.

98. Kikonyogo A, Bouamr F, Vana ML, Xiang Y, Aiyar A, Carter C, et al. Proteins related to the Nedd4 family of ubiquitin protein ligases interact with the $\mathrm{L}$ domain of Rous sarcoma virus and are required for gag budding from cells. Proc Natl Acad Sci U S A. 2001; 98: 11199-204.

99. Schuldner M, Dorsam B, Shatnyeva O, Reiners KS, Kubarenko A, Hansen HP, et al. Exosome-dependent immune surveillance at the metastatic niche requires BAG6 and $\mathrm{CBP} / \mathrm{p} 300$-dependent acetylation of p53. Theranostics. 2019; 9: 6047-62.

100. Buschow SI, Nolte-'t Hoen EN, van Niel G, Pols MS, ten Broeke T, Lauwen M, et al. MHC II in dendritic cells is targeted to lysosomes or T cell-induced exosomes via distinct multivesicular body pathways. Traffic. 2009; 10: 1528-42.

101. Katzmann DJ, Odorizzi G, Emr SD. Receptor downregulation and multivesicular-body sorting. Nat Rev Mol Cell Biol. 2002; 3: 893-905.

102. Szabo-Taylor K, Ryan B, Osteikoetxea X, Szabo TG, Sodar B, Holub M, et al. Oxidative and other posttranslational modifications in extracellular vesicle biology. Semin Cell Dev Biol. 2015; 40: 8-16.

103. Villarroya-Beltri C, Baixauli F, Mittelbrunn M, Fernandez-Delgado I, Torralba $\mathrm{D}$, Moreno-Gonzalo $\mathrm{O}$, et al. ISGylation controls exosome secretion by promoting lysosomal degradation of MVB proteins. Nat Commun. 2016; 7: 13588.

104. Kunadt M, Eckermann K, Stuendl A, Gong J, Russo B, Strauss K, et al. Extracellular vesicle sorting of alpha-Synuclein is regulated by sumoylation. Acta Neuropathol. 2015; 129: 695-713.

105. Cheng Y, Schorey JS. Targeting soluble proteins to exosomes using a ubiquitin tag. Biotechnol Bioeng. 2016; 113: 1315-24.

106. Huber J, Vales A, Mitulovic G, Blumer M, Schmid R, Witztum JL, et al. Oxidized membrane vesicles and blebs from apoptotic cells contain biologically active oxidized phospholipids that induce monocyte-endothelial interactions. Arterioscler Thromb Vasc Biol. 2002; 22: 101-7.

107. de Jong OG, Verhaar MC, Chen Y, Vader P, Gremmels H, Posthuma G, et al. Cellular stress conditions are reflected in the protein and RNA content of endothelial cell-derived exosomes. J Extracell Vesicles. 2012; 1.

108. Eldh M, Ekstrom K, Valadi H, Sjostrand M, Olsson B, Jernas M, et al. Exosomes communicate protective messages during oxidative stress; possible role of exosomal shuttle RNA. PLoS One. 2010; 5: e15353.

109. Muralidharan-Chari V, Clancy J, Plou C, Romao M, Chavrier P, Raposo G, et al. ARF6-regulated shedding of tumor cell-derived plasma membrane microvesicles. Curr Biol. 2009; 19: 1875-85.

110. Moreno-Gonzalo O, Villarroya-Beltri C, Sanchez-Madrid F. Post-translational modifications of exosomal proteins. Front Immunol. 2014; 5: 383.

111. Ageta H, Tsuchida K. Post-translational modification and protein sorting to small extracellular vesicles including exosomes by ubiquitin and UBLs. Cell Mol Life Sci. 2019; 76: 4829-48.

112. de Gassart A, Geminard C, Fevrier B, Raposo G, Vidal M. Lipid raft-associated protein sorting in exosomes. Blood. 2003; 102: 4336-44.

113. Vidal M, Mangeat P, Hoekstra D. Aggregation reroutes molecules from a recycling to a vesicle-mediated secretion pathway during reticulocyte maturation. J Cell Sci. 1997; 110 ( Pt 16): 1867-77.

114. Tan SS, Yin Y, Lee T, Lai RC, Yeo RW, Zhang B, et al. Therapeutic MSC exosomes are derived from lipid raft microdomains in the plasma membrane. J Extracell Vesicles. 2013; 2.

115. Xiu F, Cote MH, Bourgeois-Daigneault MC, Brunet A, Gauvreau ME, Shaw A, et al. Cutting edge: HLA-DO impairs the incorporation of HLA-DM into exosomes. J Immunol. 2011; 187: 1547-51.

116. Handler JS. Regulation of transport in cultured epithelia. Biol Cell. 1985; 55 : 173-5.

117. Buschow SI, Liefhebber JM, Wubbolts R, Stoorvogel W. Exosomes contain ubiquitinated proteins. Blood Cells Mol Dis. 2005; 35: 398-403.

118. Bobrie A, Colombo M, Raposo G, Thery C. Exosome secretion: molecular mechanisms and roles in immune responses. Traffic. 2011; 12: 1659-68.

119. Yokoi A, Villar-Prados A, Oliphint PA, Zhang J, Song X, De Hoff P, et al. Mechanisms of nuclear content loading to exosomes. Sci Adv. 2019; 5: eaax8849.

120. Shurtleff MJ, Temoche-Diaz MM, Karfilis KV, Ri S, Schekman R. Y-box protein 1 is required to sort microRNAs into exosomes in cells and in a cell-free reaction. Elife. 2016; 5 .

121. van Niel G, Charrin S, Simoes S, Romao M, Rochin L, Saftig P, et al. The tetraspanin CD63 regulates ESCRT-independent and -dependent endosomal sorting during melanogenesis. Dev Cell. 2011; 21: 708-21.

122. Theos AC, Truschel ST, Tenza D, Hurbain I, Harper DC, Berson JF, et al. A lumenal domain-dependent pathway for sorting to intralumenal vesicles of 
multivesicular endosomes involved in organelle morphogenesis. Dev Cell. 2006; 10: 343-54.

123. Perez-Hernandez D, Gutierrez-Vazquez C, Jorge I, Lopez-Martin S, Ursa A, Sanchez-Madrid F, et al. The intracellular interactome of tetraspanin-enriched microdomains reveals their function as sorting machineries toward exosomes. J Biol Chem. 2013; 288: 11649-61.

124. Palicharla VR, Maddika S. HACE1 mediated K27 ubiquitin linkage leads to YB-1 protein secretion. Cell Signal. 2015; 27: 2355-62.

125. Wei JX, Lv LH, Wan YL, Cao Y, Li GL, Lin HM, et al. Vps4A functions as a tumor suppressor by regulating the secretion and uptake of exosomal microRNAs in human hepatoma cells. Hepatology. 2015; 61: 1284-94.

126. Iavello A, Frech VS, Gai C, Deregibus MC, Quesenberry PJ, Camussi G. Role of Alix in miRNA packaging during extracellular vesicle biogenesis. Int J Mol Med. 2016; 37: 958-66.

127. Lasser C. Exosomal RNA as biomarkers and the therapeutic potential of exosome vectors. Expert Opin Biol Ther. 2012; 12 Suppl 1: S189-97.

128. Singh PP, Li L, Schorey JS. Exosomal RNA from Mycobacterium tuberculosis-Infected Cells Is Functional in Recipient Macrophages. Traffic. 2015; 16: 555-71.

129. Squadrito ML, Baer C, Burdet F, Maderna C, Gilfillan GD, Lyle R, et al. Endogenous RNAs modulate microRNA sorting to exosomes and transfer to acceptor cells. Cell Rep. 2014; 8: 1432-46.

130. Villarroya-Beltri C, Gutierrez-Vazquez C, Sanchez-Cabo F, Perez-Hernandez D, Vazquez J, Martin-Cofreces N, et al. Sumoylated hnRNPA2B1 controls the sorting of miRNAs into exosomes through binding to specific motifs. Nat Commun. 2013; 4: 2980.

131. Santangelo L, Giurato G, Cicchini C, Montaldo C, Mancone C, Tarallo R, et al. The RNA-Binding Protein SYNCRIP Is a Component of the Hepatocyte Exosomal Machinery Controlling MicroRNA Sorting. Cell Rep. 2016; 17: 799-808.

132. Bembom O, Keles S, van der Laan MJ. Supervised detection of conserved motifs in DNA sequences with cosmo. Stat Appl Genet Mol Biol. 2007; 6: Article8.

133. Wu B, Su S, Patil DP, Liu H, Gan J, Jaffrey SR, et al. Molecular basis for the specific and multivariant recognitions of RNA substrates by human hnRNP A2/B1. Nat Commun. 2018; 9: 420.

134. Zhang H, Deng T, Liu R, Ning T, Yang H, Liu D, et al. CAF secreted miR-522 suppresses ferroptosis and promotes acquired chemo-resistance in gastric cancer. Mol Cancer. 2020; 19: 43.

135. Gao T, Shu J, Cui J. A systematic approach to RNA-associated motif discovery. BMC Genomics. 2018; 19: 146

136. Xu YF, Hannafon BN, Khatri U, Gin A, Ding WQ. The origin of exosomal miR-1246 in human cancer cells. RNA Biol. 2019; 16: 770-84.

137. Koppers-Lalic D, Hackenberg M, Bijnsdorp IV, van Eijndhoven MAJ, Sadek P, Sie D, et al. Nontemplated nucleotide additions distinguish the small RNA composition in cells from exosomes. Cell Rep. 2014; 8: 1649-58.

138. Batagov AO, Kurochkin IV. Exosomes secreted by human cells transport largely mRNA fragments that are enriched in the 3'-untranslated regions. Biol Direct. 2013; 8: 12 .

139. Bolukbasi MF, Mizrak A, Ozdener GB, Madlener S, Strobel T, Erkan EP, et al. miR-1289 and "Zipcode"-like Sequence Enrich mRNAs in Microvesicles. Mol Ther Nucleic Acids. 2012; 1: e10.

140. Frank F, Sonenberg N, Nagar B. Structural basis for 5'-nucleotide base-specific recognition of guide RNA by human AGO2. Nature. 2010; 465: 818-22.

141. McKenzie AJ, Hoshino D, Hong NH, Cha DJ, Franklin JL, Coffey RJ, et al. KRAS-MEK Signaling Controls Ago2 Sorting into Exosomes. Cell Rep. 2016; 15: 978-87.

142. Kosaka N, Iguchi H, Yoshioka Y, Takeshita F, Matsuki Y, Ochiya T. Secretory mechanisms and intercellular transfer of microRNAs in living cells. J Biol Chem. 2010; 285: 17442-52.

143. Li Y, Zheng Q, Bao C, Li S, Guo W, Zhao J, et al. Circular RNA is enriched and stable in exosomes: a promising biomarker for cancer diagnosis. Cell Res. 2015; 25: $981-4$.

144. Jackson CE, Scruggs BS, Schaffer JE, Hanson PI. Effects of Inhibiting VPS4 Support a General Role for ESCRTs in Extracellular Vesicle Biogenesis. Biophys J. 2017; 113: 1342-52.

145. Li SP, Lin ZX, Jiang XY, Yu XY. Exosomal cargo-loading and synthetic exosome-mimics as potential therapeutic tools. Acta Pharmacol Sin. 2018; 39: $542-51$.

146. Yanshina DD, Kossinova OA, Gopanenko AV, Krasheninina OA, Malygin AA, Venyaminova AG, et al. Structural features of the interaction of the 3'-untranslated region of mRNA containing exosomal RNA-specific motifs with YB-1, a potential mediator of mRNA sorting. Biochimie. 2018; 144: 134-43.

147. Batagov AO, Kuznetsov VA, Kurochkin IV. Identification of nucleotide patterns enriched in secreted RNAs as putative cis-acting elements targeting them to exosome nano-vesicles. BMC Genomics. 2011; 12 Suppl 3: S18.

148. Kossinova OA, Gopanenko AV, Tamkovich SN, Krasheninina OA, Tupikin AE, Kiseleva E, et al. Cytosolic YB-1 and NSUN2 are the only proteins recognizing specific motifs present in mRNAs enriched in exosomes. Biochim Biophys Acta Proteins Proteom. 2017; 1865: 664-73.

149. Lin F, Zeng Z, Song Y, Li L, Wu Z, Zhang X, et al. YBX-1 mediated sorting of miR-133 into hypoxia/reoxygenation-induced EPC-derived exosomes to increase fibroblast angiogenesis and MEndoT. Stem Cell Res Ther. 2019; 10: 263.
150. Goodarzi H, Liu X, Nguyen HC, Zhang S, Fish L, Tavazoie SF. Endogenous tRNA-Derived Fragments Suppress Breast Cancer Progression via YBX1 Displacement. Cell. 2015; 161: 790-802.

151. Sun Z, Xue S, Xu H, Hu X, Chen S, Yang Z, et al. Expression profiles of long noncoding RNAs associated with the NSUN2 gene in HepG2 cells. Mol Med Rep. 2019; 19: 2999-3008.

152. Groot M, Lee H. Sorting Mechanisms for MicroRNAs into Extracellular Vesicles and Their Associated Diseases. Cells. 2020; 9.

153. Lu P, Li H, Li N, Singh RN, Bishop CE, Chen X, et al. MEX3C interacts with adaptor-related protein complex 2 and involves in miR-451a exosomal sorting. PLoS One. 2017; 12: e0185992.

154. Teng Y, Ren Y, Hu X, Mu J, Samykutty A, Zhuang X, et al. MVP-mediated exosomal sorting of miR-193a promotes colon cancer progression. Nat Commun. 2017; 8: 14448 .

155. Temoche-Diaz MM, Shurtleff MJ, Nottingham RM, Yao J, Fadadu RP, Lambowitz AM, et al. Distinct mechanisms of microRNA sorting into cancer cell-derived extracellular vesicle subtypes. Elife. 2019; 8.

156. Wang J, Chen J, Wu G, Zhang H, Du X, Chen S, et al. NRDE2 negatively regulates exosome functions by inhibiting MTR4 recruitment and exosome interaction. Genes Dev. 2019; 33: 536-49.

157. Filipenko NR, MacLeod TJ, Yoon CS, Waisman DM. Annexin A2 is a novel RNA-binding protein. J Biol Chem. 2004; 279: 8723-31.

158. Hollas H, Aukrust I, Grimmer S, Strand E, Flatmark T, Vedeler A. Annexin A2 recognises a specific region in the $3^{\prime}$-UTR of its cognate messenger RNA. Biochim Biophys Acta. 2006; 1763: 1325-34.

159. Mickleburgh I, Burtle B, Hollas H, Campbell G, Chrzanowska-Lightowlers Z, Vedeler A, et al. Annexin A2 binds to the localization signal in the $3^{\prime}$ untranslated region of c-myc mRNA. FEBS J. 2005; 272: 413-21.

160. Mathivanan S, Simpson RJ. ExoCarta: A compendium of exosomal proteins and RNA. Proteomics. 2009; 9: 4997-5000.

161. Janas T, Janas MM, Sapon K, Janas T. Mechanisms of RNA loading into exosomes. FEBS Lett. 2015; 589: 1391-8.

162. Janas T, Janas T, Yarus M. Specific RNA binding to ordered phospholipid bilayers. Nucleic Acids Res. 2006; 34: 2128-36.

163. Rajagopal C, Harikumar KB. The Origin and Functions of Exosomes in Cancer. Front Oncol. 2018; 8: 66.

164. Kohler M. [Possibilities and limitations of conservative therapy of peripheral arterial circulation disorders]. Med Welt. 1975; 26: 1855-60.

165. Tan A, Rajadas J, Seifalian AM. Exosomes as nano-theranostic delivery platforms for gene therapy. Adv Drug Deliv Rev. 2013; 65: 357-67.

166. Thery C. Cancer: Diagnosis by extracellular vesicles. Nature. 2015; 523: 161-2.

167. Wei H, Xu Y, Xu W, Zhou Q, Chen Q, Yang M, et al. Serum Exosomal miR-223 Serves as a Potential Diagnostic and Prognostic Biomarker for Dementia. Neuroscience. 2018; 379: 167-76.

168. Tan SK, Pastori C, Penas C, Komotar RJ, Ivan ME, Wahlestedt C, et al. Serum long noncoding RNA HOTAIR as a novel diagnostic and prognostic biomarker in glioblastoma multiforme. Mol Cancer. 2018; 17: 74.

169. Khan S, Jutzy JM, Valenzuela MM, Turay D, Aspe JR, Ashok A, et al. Plasmaderived exosomal survivin, a plausible biomarker for early detection of prostate cancer. PLoS One. 2012; 7: e46737.

170. Skotland T, Ekroos K, Kauhanen D, Simolin H, Seierstad T, Berge V, et al. Molecular lipid species in urinary exosomes as potential prostate cancer biomarkers. Eur J Cancer. 2017; 70: 122-32.

171. Pitt JM, Kroemer G, Zitvogel L. Extracellular vesicles: masters of intercellular communication and potential clinical interventions. J Clin Invest. 2016; 126: $1139-43$.

172. Kourembanas S. Exosomes: vehicles of intercellular signaling, biomarkers, and vectors of cell therapy. Annu Rev Physiol. 2015; 77: 13-27.

173. Susa F, Limongi T, Dumontel B, Vighetto V, Cauda V. Engineered Extracellular Vesicles as a Reliable Tool in Cancer Nanomedicine. Cancers (Basel). 2019; 11.

174. Torchilin VP. Recent advances with liposomes as pharmaceutical carriers. Nat Rev Drug Discov. 2005; 4: 145-60.

175. Rufino-Ramos D, Albuquerque PR, Carmona V, Perfeito R, Nobre RJ, Pereira de Almeida L. Extracellular vesicles: Novel promising delivery systems for therapy of brain diseases. J Control Release. 2017; 262: 247-58.

176. Sun D, Zhuang X, Xiang X, Liu Y, Zhang S, Liu C, et al. A novel nanoparticle drug delivery system: the anti-inflammatory activity of curcumin is enhanced when encapsulated in exosomes. Mol Ther. 2010; 18: 1606-14.

177. Baglio SR, Devescovi V, Granchi D, Baldini N. MicroRNA expression profiling of human bone marrow mesenchymal stem cells during osteogenic differentiation reveals Osterix regulation by miR-31. Gene. 2013; 527: 321-31.

178. Willis GR, Kourembanas S, Mitsialis SA. Toward Exosome-Based Therapeutics: Isolation, Heterogeneity, and Fit-for-Purpose Potency. Front Cardiovasc Med. 2017; 4: 63.

179. Ahmed SF, Das N, Sarkar M, Chatterjee U, Chatterjee S, Ghosh MK. Exosome-mediated delivery of the intrinsic C-terminus domain of PTEN protects it from proteasomal degradation and ablates tumorigenesis. Mol Ther. 2015; 23: 255-69.

180. Henriksen M, Johnsen KB, Andersen HH, Pilgaard L, Duroux M. MicroRNA expression signatures determine prognosis and survival in glioblastoma multiforme--a systematic overview. Mol Neurobiol. 2014; 50: 896-913.

181. Lin Q, Chen J, Zhang Z, Zheng G. Lipid-based nanoparticles in the systemic delivery of siRNA. Nanomedicine (Lond). 2014; 9: 105-20. 
182. Lai RC, Yeo RW, Tan KH, Lim SK. Exosomes for drug delivery - a novel application for the mesenchymal stem cell. Biotechnol Adv. 2013; 31: 543-51.

183. Caby MP, Lankar D, Vincendeau-Scherrer C, Raposo G, Bonnerot C. Exosomal-like vesicles are present in human blood plasma. Int Immunol. 2005; 17: 879-87.

184. Ferrantelli F, Chiozzini C, Leone P, Manfredi F, Federico M. Engineered Extracellular Vesicles/Exosomes as a New Tool against Neurodegenerative Diseases. Pharmaceutics. 2020; 12. 